\title{
Obtaining Binder for Electrode Paste from Mechanically Activated Coal
}

\author{
N. Alexander Anushenkov' ${ }^{1}$, K. Vladimir Frizorger ${ }^{2}$, N. Nikolay Dovzhenko', \\ A. Fedor Buryukin ${ }^{1}$, S.Svetlana Kositcyna ${ }^{1 *}$ \\ ${ }^{1}$ Siberian Federal University, Krasnoyarsk, Russia \\ ${ }^{2}$ RUSAL ETC LLC, Krasnoyarsk, Russia; \\ kositcyna_ss@mail.ru
}

\begin{abstract}
It is suggested that the pitch, obtained in the course of coal thermal processing, should be used as binder for manufacturing calcined anodes in aluminum industry. The investigations were carried out to determine the effect of brown and black coal mechanical processing on the degree of its organic matter conversion under thermal autoclave curing in solvent medium. It was established that under temperature of $380^{\circ} \mathrm{C}$ and pressure of less than 2.0 MPathe yield of the quinoline-soluble fraction of pitch amounts to $80 \%$ for brown coal and up to $92 \%$ for black coal of gas fat rank. It was found that the hydropercussion/cavitation processing of the water-coal suspension within a period of 15 minutes at a frequency of $55 \mathrm{~Hz}$ increases the degree of conversion of the coal organic matter by 4-6\% on average. The index of the coke residue in the pitch obtained from mechanically activated coal also increased by 3-4 \%.
\end{abstract}

Keywords: Anode Paste, Black Coal Pitch, Fluidization, Mechanical Activation, Thermal Dissolution

\section{Introduction}

Anode paste for aluminum industry both in the Russian Federation and abroad is basically prepared using the black coal as binder and the oil coke as filler. Coal pitches, obtained as the bottom products in the process of coal tar periodic and continuous distillation, even if they do formally meet the requirements of GOST10200, are not stable as regards their group composition and physical and chemical properties (viscosity, coking capacity, sintering capacity $)^{1}$. They are notable for their carcinogenic activity and their application results in poor environment not only within the working area of the electrolysis shops, but also in the near-by areas of the aluminum plants ${ }^{2}$.

Besides, over the last decade, there has been a drop in the world metallurgical coke production, and, as a consequence, in coal tar production, which is the feedstock for obtaining the pitch. The coal tar production/demand misbalance in North America and Europe makes the aluminum manufacturers buy coal pitch in East-European countries and in China, thus resulting in the price growth and deficiency. Therefore, the problem of looking for new type of binders in aluminum industry becomes ever more urgent. A feasible direction of the research in this area is developing the process to obtain binding material from coal directly, eliminating the stage of high-temperature coking in the standard technology.

The results of the experimental investigations ${ }^{3-13}$ show the principal possibility of thermal autoclave dissolution of coals. For example, by the end of the 1980s the experiments were held in New Zealand on "homogenous softening" of coal with no hydrogen gasification and with the use of different solvents under temperature of circa $360^{\circ} \mathrm{C}$ and pressure circa $1 \mathrm{MPa}$. Under laboratory

*Author for correspondence 
conditions this issue was studied in the USA (universities of Kentucky and West Virginia) and in Japan (Sumitomo, KobeSteel). The volumes of the samples obtained in the laboratories were in the range of $10-100 \mathrm{~g} / \mathrm{sample}$. The technology of Kentucky University has been tested in England with the amount of $1 \mathrm{t} /$ day in the second part of the 2000s. The obtained pitch was used for manufacturing the graphite electrodes for the electric arc furnaces (British Steel Corporation). This trend did not, however, acquire further development due to economic reasons.

Due to the fact that in the high-temperature coking process the polyaromatic hydrocarbon synthesis occurs at a temperature of higher than $800^{\circ} \mathrm{C}$, it can reasonably be assumed that when the pitch is obtained under comparatively low temperatures $\left(350-400^{\circ} \mathrm{C}\right)$ the synthesis of carcinogenic polycyclic hydrocarbons does not occur, and, as a consequence, the content of benzopyrene in such pitches will be 2-4 times lower, than that in the conventional binder. At that, the data on the experimental investigations indicate that the obtained product of thermal autoclave coal dissolution does not meet in full the requirements to the anode paste binder.The principally meaningful indicators, determining the possibility of its application, are represented by low coke residue, high ash content, mass fraction of volatile matters. All the above mentioned, as a whole, impedes generating the homogenous structure of calcined anode, decreases its mechanical strength.

Improving the Organic Matter of Coal (OMC) conversion into the pitch products is possible by means of mechanical activation of coal.

Mechanical activation of hard matters in the crushing devices is a technologically convenient technique, which allows the mechanical energy impulse to feed to the processed matter. Different active states which occur in the course of mechanical activation and the accelerated mass transfer processes ensure the effective heterogeneous mechanochemical reactions under mechanical processing.

The hydrodynamics processes of affecting different materials are the basis for many technological and manufacturing processes in different industries: chemical, petrochemical, coal mining, ore-mining, microbiological, food industry, pharmaceutical, perfumery, paintand- varnish industry, mechanical engineering and many others.

There has been successful experience in applying the mechanical activation processes in black and brown coal fluidization and gasification ${ }^{14-20}$, as well as in the coal pitch mechanical activation process ${ }^{21}$. It was proved that coal fluidization and gasification increases the yield of the liquid products and alters their qualitative composition by means of mechanochemical activation.

Analyzing the literature reports it can be maintained that the coal mechanical activation processes, including that in the solvent medium, will make it possible to obtain the stable suspensions for further fluidization. By means of modifying the composition and the structure of coal and by increasing its reaction capacity the mechanical activation of coals in the reducing media and in the presence of donor-hydrogen solvents will also increase the yield of soluble products in further processing.

\section{Materials and Methods}

\subsection{Description of the Coal Hydropercussion/Cavitation Processing Unit}

The coal ranks G, GZh, 2BR, selected as feedstock for the process of thermal dissolution, under went several stages of crushing followed by mechanical activation.

The operation of initial coal crushing was implemented by jaw crusher Pulverisette ${ }^{1}$. Further crushing down to sizes less than $1.0 \mathrm{~mm}$ was done in the Pulverisette 13 disk mill. The crushed coal then went through wet screening at dressing machine Analysette 3equipped with the sieve set $\mathrm{d}=200 \mathrm{~mm}, \mathrm{~h}=50 \mathrm{~mm}$.

Upon screening, the coal sizes larger than $1.0 \mathrm{~mm}$ were processed in the field of hydropercussion/cavitation impulses in resonant disruption mode at the laboratory hydropercussion/cavitation powder distributing unit (Figure 1). The sketch of the unit operating pair is shown in Figure 2.

The unit was charged with the coal-water mixture; the hard fraction content in the mixture amounted to $67 \%$. The rotor rotation frequency in the cavitation chamber was $50 \mathrm{~Hz}(3,000 \mathrm{rpm})$.

In the dynamic Hydropercussion/Cavitation Units (HCUs) the flow is disrupted due to rotations of the rotor part which is placed coaxially to the stator. Functionally, in the operating surfaces of the rotor and of the stator of this unit the slits are arranged to enable the process medium flow. One of the basic factors of HCU efficiency is the shape of those slits cross section, the mode of their movement and the clearance between the stator and the rotor parts. 


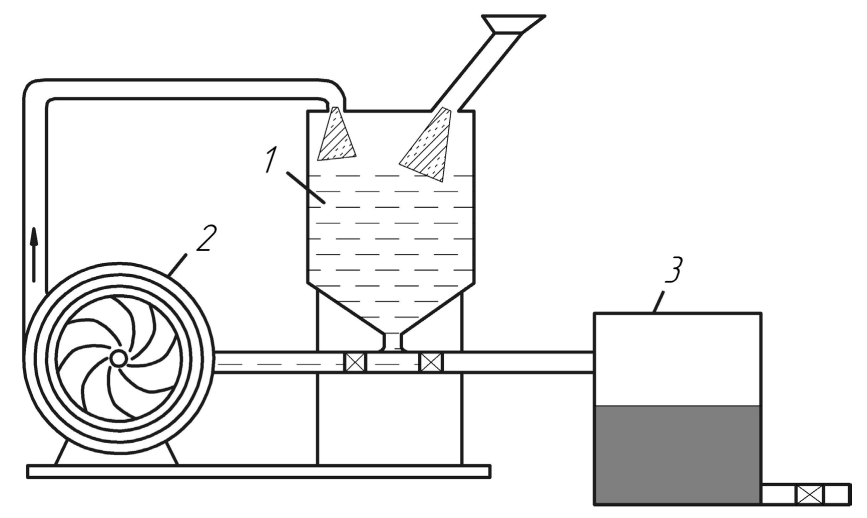

Figure 1. Schematics of hydropercussion/cavitation powder distributing unit: 1 - feedstock vessel, 2 - centrifugal compartment, 3 - mechanically activated coal receiver.

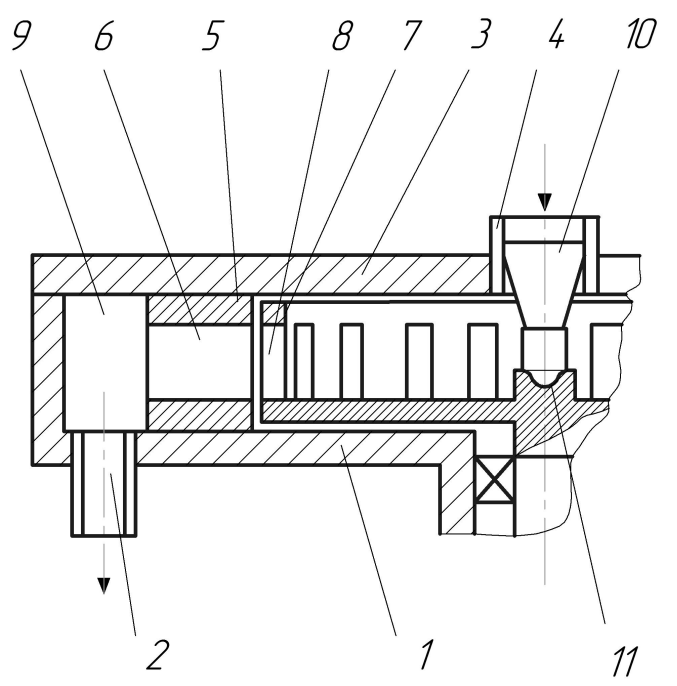

Figure 2. Schematics of hydropercussion/cavitation unit (HCU) operating pair: 1 - housing; 2 - outlet; 3 - cover; 4 - outlet; 5 - stator part; 6 - slits in the side walls; 7 - rotor part with the slits in the side walls; 8 - slits in the rotor part; 9 - operating chamber; 10 - converging tube; 11 - deflector.

HCUs are applied for processing such systems as "liquid-liquid", "liquid-hard matter"and "gas-liquid" due to the mechanical effect on the particles of the processed medium, including the impact, shearing and abrasive loads at stator/rotor operating pair contacts and also due to the hydrodynamic effect, represented by high shear stresses in liquid, pressure pulsation and the medium flow velocity, as well as due to hydroacoustic effect on the processed medium, manifested in fine pressure pulsations, intensive cavitation, impact wavesand non-linear acoustic effects. Within the unit the low concentration energy is transformed into the energy with high local concentration at the unstable locations of the matter structure. The energy concentration in space and time helps achieving more powerful impulse effect, performing the energy excitation, releasing the inner energy of the matter, initiating multiple quantum catalytic processes, chain processes, spontaneous burst-type and other energy charged processes.

The dispersion in hydraulic crushing occurs when a particle is affected by a sequence of hydraulic impact impulses with a frequency comparable with that of the particle internal destruction impulsesthat is in the mode of resonant disruption. Often the pulse frequency and height are predetermined by the frequency of the rotor rotations and by the constructive features of the centrifugal hydroshock/cavitation chamber of the powder distributing unit.

The grain size distribution of the crushed coal was determined at the size distribution analyzer HORIBALA-300.

\subsection{Thermal autoclave coal processing}

The crushed coal was dried in the vacuum dewatering box till the residual moisture content amounted to not more than $1.0-1.5 \%$ wt at a temperature of $80^{\circ} \mathrm{C}$ and at the draft intensity index of $80 \mathrm{~mm}$ mercury column, then it was mixed with the solvent (anthracene fraction of coal tar) to the ratio of 2:1 and was put to autoclave processing in the rotating pressure chamber with volume of $80 \mathrm{ml}$ (the velocity of the autoclave rotation was $80 \mathrm{rpm}$ ). The heating rate amounted to $4-5^{\circ} \mathrm{C} / \mathrm{min}$, maximum heating temperature was $380^{\circ} \mathrm{C}$; the duration of isothermal exposure took 1 hour. The feedstock was being charged into the rotating autoclave with the rate of $4 \mathrm{~g}$ of coal and $8 \mathrm{~g}$ of anthracene fraction.

The product of the coal autoclave processing underwent extraction in Soxhlet apparatus with heptane and toluene in sequence. The insoluble residue underwent extraction with quinoline. The degree of the coal organic matter conversion was estimated by measuring the alteration of ash mass ratio in the feed coal and in the quinoline - insoluble residue. The coke residue was estimated according to ISO 6998.

\section{Results and Discussion}

For the purposes of controlling the coal grain size distribution in the course of crushing, the samples were taken at definite controlled intervals. The data are given in Table 1. 
Table 1. Results of the screening analysis of the coal dust fraction, obtained in the powder distribution machine at different intervals of processing, exemplified by coal rank GZh.

\begin{tabular}{|c|c|c|c|c|c|c|}
\hline \multirow{2}{*}{$\begin{array}{l}\text { Grain } \\
\text { sizes, } \\
\text { mm }\end{array}$} & \multirow{2}{*}{$\begin{array}{l}\text { Content } \\
\text { in the } \\
\text { feed } \\
\text { material, } \\
\%\end{array}$} & \multicolumn{5}{|c|}{ Time, min } \\
\hline & & 2 & 5 & 10 & 20 & 30 \\
\hline+1 & 14.73 & 0.00 & 0.00 & 0.00 & 0.00 & 0.00 \\
\hline$-1+0.5$ & 43.21 & 6.64 & 2.43 & 0.5 & 0.52 & 0.21 \\
\hline$-0.5+0.2$ & 38.22 & 56.19 & 44.27 & 30.69 & 15.75 & 12.53 \\
\hline $0.2+0.1$ & 3.36 & 17.59 & 25.52 & 33.83 & 46.98 & 47.94 \\
\hline-0.1 & 0.53 & 19.57 & 27.77 & 34.98 & 36.74 & 39.3 \\
\hline
\end{tabular}

Table 1 shows that in the process of hydroshock/cavitation crushing for $30 \mathrm{~min}$, the content of large fractions with grain sizes of more than $0.2 \mathrm{~mm}$ becomes smaller. At that, the major amount of sizes $-0.1+0.5 \mathrm{~mm}$ are reduced within the first $5 \mathrm{~min}$ of processing, and after $10 \mathrm{~min}$ they disappear from the charge composition completely. Grain sizes $-0.5+0.2 \mathrm{~mm}$ are reduced slower, and after 30 minutes there are only $12.55 \%$ of them in the charge. The reduction of large fractions is the cause of accumulating the fractions with grain sizes of less than $0.2 \mathrm{~mm}$, the content of which increases in monotone within the first 10 min of crushing, thereupon the amount of those fractions in the charge riches some limit of dispersion. Accumulation of grain sizes $0.1 \mathrm{~mm}$ is depicted in Figure 3 .

Figure 3 shows that the alteration in the amount of fraction $-0.1 \mathrm{~mm}$ at hydraulic reduction has an asymptotic character: in the beginning of the processing the content of fraction increases rapidly, after 15 min of crushing it

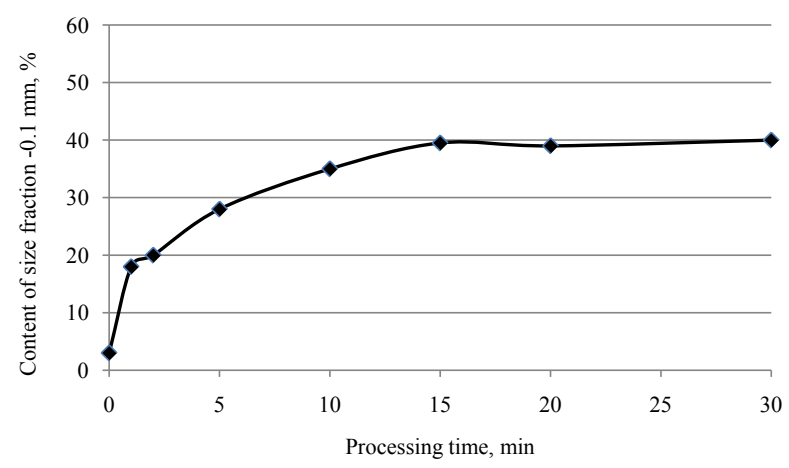

Figure 3. Grain size $0.1 \mathrm{~mm}$ content versus process duration. comes to a plateau and practically does not alter in the course of further processing. This enables a conclusion on the stabilizing character of the reduction process in hydropercussion/cavitation unit with a stable frequency. Obviously, the limit degree of fineness will be determined by the ratio of hydraulic impact frequency and the internal frequency of the particle destruction.

To confirm this assumption an experiment has been carried out altering the frequency of hydropercussion/ cavitation effect (Figure 4). Altering the rotor rotation frequency in the powder distributing unit by regulating the industrial frequency of the electric drive feeding power from $20 \mathrm{~Hz}$ to $60 \mathrm{~Hz}$ allows altering the frequency of hydraulic impact impulses in the existing structure from $0.7 \mathrm{kHz}$ to $2.0 \mathrm{kHz}$. The diagram represented in Figure 4 depicts vividly the occurrence of resonant reduction of coal fraction $-0.5+0.2 \mathrm{~mm}$ at the rotor rotation frequency of $55 \mathrm{~Hz}$. At this frequency the smooth reduction of the charged fraction from $53 \%$ to $42 \%$ is replaced by a sudden jump to $15 \%$. At that, a parallel jump is observed in increasing the content of fraction $-0.2+0.1 \mathrm{mmfrom} 25 \%$ to $43 \%$.

Thus, by altering the frequency of processing it is possible to regulate the resulting grain size distribution of coal in water. At that, intensive selective reduction process ensures not only the required grain size distribution parameters of coal, but alsothe homogeneity and viscosity of the coal-water composition.

Based on the preliminary experiments the optimum duration of the coal samples reduction (15 min.) and the frequency of hydropercussion/cavitation processing $(55 \mathrm{~Hz})$ were established. Table 2 shows the data on the grain size distribution in the crushed coals and on differential size distribution of chemically activated coals,

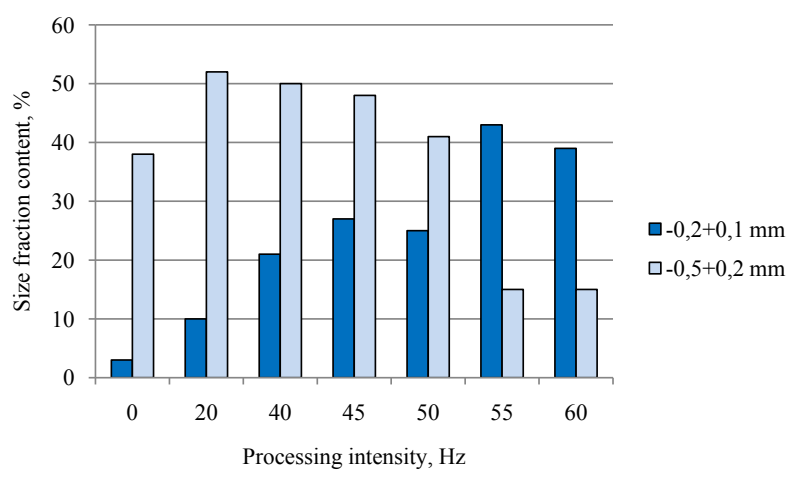

Figure 4. Effect of processing frequency on the content of the controlled fractions for coal rank GZh. 
Table 2. Grain size distribution of coal

\begin{tabular}{|l|c|c|c|c|}
\hline \multirow{2}{*}{ Coal } & \multicolumn{5}{|c|}{ Ratio of coal particle size fractions, $\boldsymbol{\mu m}$} \\
\cline { 2 - 5 } & $<\mathbf{1 0} \boldsymbol{\mu m}$ & $<\mathbf{5 0} \boldsymbol{\mu m}$ & $<\mathbf{1 0 0} \boldsymbol{\mu m}$ & $<500 \mu \mathrm{m}$ \\
\hline \multicolumn{5}{|c|}{ after mechanical activation } \\
\hline 2B & 4 & 21 & 31 & 100 \\
\hline 2GR & 3 & 14 & 23 & 100 \\
\hline 1GZhR & 5 & 17 & 24 & 100 \\
\hline \multicolumn{5}{|c|}{ without mechanical activation } \\
\hline 2B & 6 & 28 & 42 & 100 \\
\hline 2GR & 4 & 24 & 46 & 100 \\
\hline 1GZhR & 7 & 28 & 49 & 100 \\
\hline
\end{tabular}

Table 3. Process indicators. Thermal coal dissolution in solvents and anthracene oil mixture $\left(\mathrm{T}_{\text {reaction }} 380^{\circ} \mathrm{C}\right.$, duration of reaction 1 hour)

\begin{tabular}{|l|c|c|c|c|c|}
\hline $\begin{array}{l}\text { Coal } \\
\text { rank }\end{array}$ & $\begin{array}{c}\text { OMC } \\
\text { conversion, } \\
\text { mass. } \%\end{array}$ & \multicolumn{2}{|c|}{$\begin{array}{c}\text { Product composition, mass.\% } \\
\text { calculated for paste }\end{array}$} & $\begin{array}{c}\text { Cokere- } \\
\text { sidue, } \% \\
\text { mass. }\end{array}$ \\
\cline { 3 - 6 } & $\begin{array}{r}\text { toluene } \\
- \text { soluble }\end{array}$ & $\begin{array}{c}\text { quinolene } \\
\text { - soluble }\end{array}$ & $\begin{array}{c}\text { insoluble } \\
\text { residue }\end{array}$ & \\
\hline B & 38 & 68 & 80 & 20 & 28 \\
\hline G & 46 & 74 & 83 & 17 & 33 \\
\hline GZh & 62 & 77 & 88 & 12 & 34 \\
\hline & without mechanical activation & & \\
\hline B & 42 & 72 & 82 & 18 & 31 \\
\hline G & 53 & 75 & 86 & 13 & 36 \\
\hline GZh & 68 & 79 & 92 & 8 & 38 \\
\hline
\end{tabular}

and of the coals which went through the disc mill and through screening off the fraction larger than $0.1 \mathrm{~mm}$. Table 2 demonstrates that in the processed reduced coals (fractions smaller than $0.5 \mathrm{~mm}$ ) the ratio of the particles with sizes less than 100 micrometer amounts to $23 \%$ up to $42 \%$, less than 50 micrometer amounts to 17 up to $33 \%$.

The results of estimating the degree of coal conversion in autoclave processing in the coal tar anthracene fraction medium are presented in Table 3.

When the process was implemented in the anthracene oil medium the regular alteration in coal activity depending on the carbonization degree was observed: the higher the carbonization degree, the more activity the coal reveals under thermal dissolution. The most active among the recommended samples proved to be coal ranks GZh, and also G; the content of the quinolene-insoluble residue in the product amounted to 8 up to $13 \%$.
The data represented in Table 3 show, that a slow but stable increase in OMC conversion degree is observed for all investigated samples. The strongest effect of mechanical activation on increasing the content of toluene- and quinolene-soluble matters in the autoclave process products is observed in highly-metamorphic coal ranks GZh, and, to a lesser degree, in coal rank $\mathrm{G}$. The content of the insoluble residue in all coals decreased by 3-4\% on average.

The coke residue index implies the degree of aromatization of the autoclave process products. The extraction obtained from the mechanically activated coals is marked by large amount of coke residue in all investigated coal ranks.

\section{Conclusion}

Thus, it has been experimentally proved that in the course of further development and more profound investigations the mechanical activation and mechanochemical activation of coals will become prospective directions for solving the issue of obtaining coal pitch with the required composition and quality. In combination with thermal coal autoclave processing under quite mild conditions (temperature of $380^{\circ} \mathrm{C}$, pressure 1.4-2.0 MPa) with no additional hydrogen gasification processing and with no catalysts, the coal OMC conversion degree can be increased by 3-4\%. In the course of processing the mechanically activated coal the increase in coking capacity of the obtained pitch-like products was observed as well as the increase in toluene- and quinolene-soluble matters content.

\section{Acknowledgements}

The authors acknowledge the support by Federal Target Program "Researches and development on the priority directions of development of scientific technological complex of Russia for 2014-2020", Action 1.3 "Carrying out the applied researches directed on creation of advanced scientific-technological potential for development of branches of economy" (the Agreement No. 14.578.21.0005 of 05.06.2014, unique identifier of applied researches (project) RFMEFI57814X0005).

\section{References}

1. Sidirov OF, Seveznev AN. Perspektivyproizvodstva I sovershenstvovaniyapotrebitelskihsvoystvkamennougolnyhelectodnihpekov Prospects for production and improvement 
of consumer properties of coal tar pitch electrode. 2006; $\mathrm{L}(1): 16-24$.

2. Andrésen JM. Reducing emissions of polyaromatic hydrocarbons from coal tar pitches. Environmental challenges and greenhouse gas control for fossil fuel utilization in the 21st Century. US: Springer; 2002. p 59-72. DOI 10.1007/978-1-4615-0773-4_5

3. Mochida I, Korai Y, Ku C-H, Watanabe F, Sakai Y. Chemistry of synthesis, structure, preparation and application of aromatic-derived mesophase pitch. Carbon. 2000; 38: 305-28.

4. Bartle KD, Martin TG, Williams DF. Chemical nature of a supercritical-gas extract of coal at $350{ }^{\circ} \mathrm{C}$. Fuel.1975; 54(4):226-35.

5. Kershaw JR, Overbeek J, Bagnell LJ. Supercritical gas extraction of Victorian brown coals: The effect of coal properties. Fuel. 1985; 64(8):1070-4.

6. Kuznetsov PN, Yoshda T, Kuznetsova LI. Coal liquefaction technology level in Japan. Solid Fuel Chemistry. 1995; 4:18-28.

7. Technical and economical assessment of mild coal extraction. Subcontract No 2691-UK-DOE-1874. Final report. University of Kentucky, Center for Applied Energy Research and New Carbon LLC, Consortium for premium carbon products from coal. 2005.

8. Rahman M, Samanta A, Gupta R. Production and characterization of ash-free coal from low-rank Canadian coal by solvent extraction. Fuel Processing Technology. 2013; 115:88-98.

9. Shui H, Zhou Y, Li H, Wang Z, Lei Z, Ren S, Pan C, Wang W. Thermal dissolution of Shenfu coal in different solvents. Fuel. 2013; 108: 385-90.

10. Okuyama N, Furuya A, Komatsu N, Shigehisa T. Proceedings Intern. Conf. on Coal Science and Technology. Okinawa; 2005.

11. Ihnatowicz M, Kulezycka I. Fifth and internat Pittsburgh Coal Conference. University of Pittsburgh; 1988 Sep 25-29. p. 613.

12. Cheng X, Li G, Peng Y, Song Sh, Shi X, Wu J, Xie J, Zhou $\mathrm{M}, \mathrm{Hu}$ G. Obtaining needle coke from coal liquefaction residue. Chemistry and Technology of Fuels and Oils. 2012; 48(5):349-55.

13. Andrews R. Mild coal extraction for the production of anode coke. Light Metals. 2009;963-8.

14. Kuznelsov PN, Kuznetsova LI, Kazbanova AV, Buryukin FA. The effect of mechanical impact of high energy on the structural properties of brown coal and the reactivity for liquefaction. ARPN Journal of Engineering and Applied Sciences. 2015; 10(16):6980-7.

15. Laouafa F, Farret R, Vidal-Gilbert S, Kazmierczak J-B. Overview and modeling of mechanical and thermomechanical impact of underground coal gasification exploitation. Mitigation and Adaptation Strategies for Global Change, 2014. 2014 Mar. DOI 10.1007/s11027-014-9542-y

16. Kuznetsov PN, Kuznetsova LI, Buryukin FA, Marakushina EN, Frizorger VK. Methods for the preparation of coaltar pitch. Solid Fuel Chemistry. 2015; 49(4):213-25. DOI: 10.3103/S0361521915040059

17. Patrakov UF, Fedorova NI, Fedyaeva ON. The intensification of the process of coal liquefaction mechano-chemical activation. Intensifikatcyaprocessaozhizhenyaugleymahanokhimicheskoyaktivatcyey. Chemistry for Sustainable Development. 2005; 13:299-303.

18. Kairbekov ZK, Eshova ZT, Myltykbaeva ZK. Research of mechanochemical processing of coal hydrogenation. International Journal of Applied and Fundamental Science. 2012; 8:45-9. Available from: http://elibrary.ru/item. asp? id $=17955298$.

19. Surkov VG, Pevneva GS, Golovko AK, Mozhaiskaya MV. Effect of mechanical treatment temperature on the composition of the organic matter of brown coal. Solid Fuel Chemistry, 2013; 47 (1):7-10. DOI: 10.3103/S0361521913010084

20. Proidakova AG, Kalabin GA. Oxidation of coals in the course of mechanical treatment. Solid Fuel Chemistry. 2009; 43(2):86-93. DOI: 10.3103/S0361521909020050

21. Anushenkov AN, Rostovtsev VI, Frizorger VK. Modification of coal tar pitch in hydropercussion-cavitation field. Journal of Mining Science. 2009; 45(5):509-16. 